\title{
Length-of-day and space-geodetic determination of the Earth's variable gravity field
}

Received: 17/02/2007 / Accepted: 27/07/2007

\begin{abstract}
The temporal variations of the Earth's gravity field, nowadays routinely determined from Satellite Laser Ranging (SLR) and GRACE, are related to changes in the Earth's rotation rate through the Earth's inertia tensor. We study this connection from actual data by comparing the traditional length-of-day (LOD) measurements provided by the International Earth Rotation and reference systems Service (IERS) to the variations of the degree- 2 and order- 0 Stokes coefficient of the gravity field determined from fitting the orbits of the LAGEOS 1 and 2 satellites since 1985. The two series show a good correlation (0.62) and similar annual and semi-annual signals, indicating that the gravity-field-derived LOD is valuable. Our analysis also provides evidence for additional signals common to both series, especially at a period near 120 days, which could be due to hydrological effects.
\end{abstract}

Keywords Earth rotation · length-of-day · gravity field · $C_{20} \cdot$ satellite laser ranging $\cdot$ LAGEOS

\section{Introduction}

Studies of the Earth's rotation are aimed at modeling its variations as precisely as possible, on the basis of geodetic measurements and geophysical models. Offsets with respect to a uniform rotation around a fixed axis or an analytical model are described by the Earth's Orientation Parameters (EOPs). These parameters consist of the polar motion coordinates, the celestial pole offsets and the Earth's rotation rate.

The Length-of-day (LOD) is used to characterize the variability of the Earth's rotation rate. The LOD variations are due to gravitational effects from external bodies (i.e., lunisolar tides; Defraigne and Smith 1999), but also originate from geophysical deformations occuring in various layers

\section{G. Bourda}

Centre National de Recherche Scientifique (CNRS), Observatoire Aquitain des Sciences de l'Univers (OASU),

Unité Mixte de Recherche 5804, Université Bordeaux 1, 33270 Floirac, France

E-mail: geraldine.bourda@obs.u-bordeaux1.fr of the Earth (i.e., atmosphere, oceans, hydrosphere, mantle, core; Barnes et al. 1983; Gross et al. 2004).

Each of the geophysical contributions to the LOD variations is traditionally divided into (i) a motion term, and (ii) a mass term (Barnes et al. 1983; Eubanks 1993). This comes from the Euler-Liouville equations for the angular momentum conservation (Munk and McDonald 1960). For example, the atmosphere acts on the LOD variations through the effect of the winds (motion term) and the effect of the atmospheric pressure onto the crust (mass term). The motion contribution to the LOD variations may be modeled from the data gathered by the Special Bureau for the Atmosphere (SBA) and the Special Bureau for the Oceans (SBO), depending on the Global Geophysical Fluid Center (GGFC) from the International Earth Rotation and reference systems Service (IERS).

The mass contribution is due to dynamical processes in the Earth system that affect the mass distribution (it is equivalent to gravitational effects). The Earth's mass distribution, described by the inertia tensor, also acts directly on the Earth's gravity field, therefore implying a relationship between the LOD and gravity field variations (Lambeck 1988; Chao 1994; Gross 2001).

The purpose of the study presented here is the investigation of this relationship by comparison of standard LOD measurements with gravity field data, in order to determine if the latter could be useful to supplement classical LOD estimates. The motivation also originates in the requirement to prepare for the ambitious project GGOS (Global Geodetic Observing System) of the IAG (International Association of Geodesy), which ultimate goal is a consistent and integrated treatment of the three pillars of geodesy (Rummel et al. 2005): (1) the geometry and deformation of the Earth's surface, (2) the Earth's rotation and orientation, and (3) the Earth's gravity field and its temporal variations.

LOD data used in geodesy, geophysics or astronomy come from the combination of the results from various geodetic observation techniques. Very Long Baseline Interferometry (VLBI) is the primary technique, which permits determination of all the EOPs (Schuh and Schmitz-Hübsch 2000; 
Schlüter and Behrend 2007). Global Positionning System (GPS) and Satellite Laser Ranging (SLR) allow to obtain polar motion coordinates and LOD (Lichten at al. 1992; Tapley et al. 1985), while Doppler Orbitography by Radiopositioning Integrated on Satellite (DORIS) and Lunar Laser Ranging (LLR) may be selectively used for such determinations (Gambis 2006; Dickey and Williams 1983).

Gravity field data, represented in the form of Stokes coefficients, are nowadays routinely obtained by precise orbitography of geodetic satellites (for example based on SLR measurements; Nerem et al. 1993; Tapley et al. 1993; Biancale et al. 2000) or dedicated space gravimetric missions like CHAMP (CHAllenging Minisatellite Payload; Reigber et al. 2002) or GRACE (Gravity Recovery And Climate Experiment; Reigber et al. 2005).

Several studies have already investigated (i) the longterm variation (Yoder et al. 1983; Rubincam 1984; Cheng et al. 1997; Cox and Chao 2002; Dickey et al. 2002) and (ii) the seasonal variations (Chao and Au 1991; Chao and Eanes 1995; Chao and Gross 1987; Gegout and Cazenave 1993; Cheng and Tapley 1999) of the Stokes coefficients, especially the degree-2 and order- 0 coefficient $C_{20}$, which characterizes the gravitational oblateness of the Earth.

Variations of the gravity field have also been investigated by using EOP data (Chen et al. 2000; Chen and Wilson 2003; Chen et al. 2005). Bourda $(2004,2005)$ and Yan et al. (2006) instead derived LOD and polar motion from temporal series of the $C_{20}, C_{21}$ and $S_{21}$ Stokes coefficients.

This study is focused on the LOD parameter. For this purpose, we compare the LOD series derived from the $C_{20}$ variations (hereafter referred to as geodetic data) to the standard LOD series derived mainly from VLBI, GPS and SLR (hereafter referred to as astrometric data). These two types of data are not entirely equivalent: (1) the astrometric data are relative to the crust of the Earth, whereas the geodetic data are relative to the entire Earth measured from space (Chao 2005); (2) the astrometric data are sensitive to all geophysical processes inducing variations of the LOD (i.e., the mass and motion terms), whereas the geodetic data are only sensitive to gravitational effects into the Earth system (i.e., the mass terms). These differences will be accounted for when comparing the two LOD series.

In the following, we first detail the equations linking the LOD and the $C_{20}$ Stokes coefficient (Lambeck 1988; Gross 2001; Chen et al. 2005). Then, we present the data used for our study and the processing to determine the corresponding LOD variations. The standard LOD data used for comparison come from the IERS and results from a combination of mainly VLBI, GPS and SLR measurements. The gravity field data were obtained by the GRGS/CNES (Groupe de Recherche de Géodésie Spatiale/Centre National d'Etudes Spatiales, Toulouse, France) on the basis of SLR orbitography (LAGEOS I and II gravity field data). We could have used GRACE data, but the $C_{20}$ Stokes coefficient series derived from GRACE measurements are known to show a longterm drift and are thus less accurate than those from SLR (personal communication from Lemoine 2004). In addition, SLR data cover a much longer period than GRACE data (20 years for SLR against 5 years for GRACE), which is more interesting for comparison of LOD measurements.

We compare the LOD mass terms obtained from both series by determining the correlation coefficient between the two series and by estimating annual and semi-annual signals with a Fourier analysis. We also investigate the intraseasonal terms that remain in each of the series after this Fourier analysis. Finally, we discuss the consistency of the results and draw further prospects about using gravity field data to supplement current LOD measurements.

\section{Theory}

\subsection{Earth's tensor of inertia}

The Earth's tensor of inertia $\underline{\underline{I}}$, characterizing the mass distribution in the Earth system (i.e., solid Earth, atmosphere, oceans, hydrosphere), is defined in the terrestrial frame (Oxyz) by:

$\underline{I}(t)=\left[\begin{array}{lll}I_{11} & I_{12} & I_{13} \\ I_{12} & I_{22} & I_{23} \\ I_{13} & I_{23} & I_{33}\end{array}\right](t)$

with:

$I_{11}=\int_{y} \int_{z}\left(y^{2}+z^{2}\right) \mathrm{d} M \quad I_{12}=-\int_{x} \int_{y} x y \mathrm{~d} M$

$I_{22}=\int_{x} \int_{z}\left(x^{2}+z^{2}\right) \mathrm{d} M \quad I_{23}=-\int_{y} \int_{z} y z \mathrm{~d} M$

$I_{33}=\int_{x} \int_{y}\left(x^{2}+y^{2}\right) \mathrm{d} M \quad I_{13}=-\int_{x} \int_{z} x z \mathrm{~d} M$

where $M$ is the mass of the Earth.

In practice, the Earth is not only considered as an ellipsoid of rotation but also as a deformable body. For this reason, its tensor of inertia is not diagonal. Then, $\underline{I}$ may be written as:

$\underline{I}(t)=\left[\begin{array}{lll}A & 0 & 0 \\ 0 & B & 0 \\ 0 & 0 & C\end{array}\right]+\left[\begin{array}{lll}c_{11} & c_{12} & c_{13} \\ c_{12} & c_{22} & c_{23} \\ c_{13} & c_{23} & c_{33}\end{array}\right](t)$

where $A, B$ and $C$ are the mean principal moments of inertia (representing the part of the tensor that is constant with time) and $c_{i j}$ (for $i, j=1,2,3$ ) are the products of inertia (representing the shift to the mean ellipsoidal solid Earth) such that each of the $c_{i j} / C$ is very small.

\subsection{Earth's Gravity Field}

The Earth's gravity field $U(r, \phi, \lambda)$ is traditionally developed into spherical harmonics (Kaula 1966):

$$
\begin{array}{r}
U(r, \phi, \lambda)=\frac{G M}{r} \sum_{n=0}^{+\infty} \sum_{m=0}^{n}\left(\frac{R_{e}}{r}\right)^{n}\left(C_{n m} \cos m \lambda\right. \\
\left.+S_{n m} \sin m \lambda\right) P_{n m}(\sin \phi)
\end{array}
$$


where $r$ is the geocentric distance, $\phi$ is the geocentric latitude and $\lambda$ is the longitude of the determination point; $G$ is the gravitational constant and $R_{e}$ is the mean equatorial radius of the Earth. $C_{n m}$ and $S_{n m}$ are the Stokes coefficients, defined by:

$$
\left.\begin{array}{l}
C_{n m} \\
S_{n m}
\end{array}\right\}=\frac{\left(2-\delta_{0 m}\right)}{M R_{e}^{n}} \frac{(n-m) !}{(n+m) !} \int_{M} r^{n} P_{n m}(\sin \phi)\left\{\begin{array}{c}
\cos m \lambda \\
\sin m \lambda
\end{array}\right\}
$$

where $(r, \phi, \lambda)$ are the coordinates of the mass element $d M$ in the terrestrial reference frame $(O x y z), P_{n m}(\sin \phi)$ are the Legendre polynomials (Lambeck 1988), and $\delta_{0 m}=1$ if $m=$ 0 or $\delta_{0 m}=0$ if $m \neq 0$. We can notice that in practice, the normalized Stokes coefficients $\bar{C}_{n m}$ and $\bar{S}_{n m}$ are generally used (Lambeck 1988).

In order to take into account the yielding of the solid Earth as the surface mass is redistributed, a loading coefficient $\left(1+k_{n}^{\prime}\right)$ is generally applied into the right hand side of Eq. (5) (see Chen et al. 2005), then $C_{20}$ may be further expressed as:

$$
\begin{aligned}
C_{20} & =\left(1+k_{2}^{\prime}\right) \frac{1}{2 M R_{e}^{2}} \int_{M} r^{2}\left(3 \sin ^{2} \phi-1\right) \mathrm{d} M \\
& =\left(1+k_{2}^{\prime}\right) \frac{1}{2 M R_{e}{ }^{2}} \int_{M}\left(3 z^{2}-r^{2}\right) \mathrm{d} M \\
& =\left(1+k_{2}^{\prime}\right) \frac{1}{2 M R_{e}{ }^{2}} \int_{M}\left(2 z^{2}-x^{2}-y^{2}\right) \mathrm{d} M
\end{aligned}
$$

where $k_{2}^{\prime}=-0.301$ is the load Love number of degree 2 (Farrel 1972). Finally, after introducing in Eq. (6) the components of the inertia tensor defined in Eq. (2), one obtains:

$$
\begin{aligned}
C_{20} & =\left(1+k_{2}^{\prime}\right) \frac{1}{2 M R_{e}^{2}}\left[-I_{33}+\left(I_{11}+I_{22}-I_{33}\right)\right] \\
& =\left(1+k_{2}^{\prime}\right) \frac{1}{M R_{e}{ }^{2}}\left[\frac{I_{11}+I_{22}}{2}-I_{33}\right],
\end{aligned}
$$

which relates the $C_{20}$ Stokes coefficient to the inertia tensor.

\subsection{Relation between $C_{20}$ variations and the inertia tensor}

On the basis of Eq. (7), the inertia tensor component $I_{33}$ can be related to the degree- 2 and order- 0 Stokes coefficient $C_{20}$ by (Lambeck 1988; Gross 2001):

$I_{33}(t)=\frac{I_{11}+I_{22}}{2}(t)-M R_{e}{ }^{2} \frac{C_{20}(t)}{1+k_{2}^{\prime}}$

Using the trace of the inertia tensor $\operatorname{Tr}(I)=I_{11}+I_{22}+I_{33}$ (i.e., the sum of its diagonal elements), Eq. (8) can be further expressed as:

$I_{33}(t)=\frac{1}{3} \operatorname{Tr}(I)(t)-\frac{2}{3} M R_{e}^{2} \frac{C_{20}(t)}{1+k_{2}^{\prime}}$
Then, from Eq. (3), the product of inertia $c_{33}$ (i.e., $I_{33}-C$ ) can be written:

$c_{33}(t)=\frac{1}{3} \Delta \operatorname{Tr}(I)-\frac{2}{3} M R_{e}^{2} \frac{\Delta C_{20}(t)}{1+k_{2}^{\prime}}$

where $\Delta \operatorname{Tr}(I)$ is the change in the trace of the Earth's inertia tensor following mass redistribution, and $\Delta C_{20}(t)$ is the corresponding shift in the Stokes coefficient $C_{20}$.

2.4 Link between LOD and gravity field through the inertia tensor

Assuming that the instantaneous Earth's rotation vector is given by: $\vec{\omega}=\left(\omega_{1}, \omega_{2}, \omega_{3}\right)^{T}=\Omega\left(m_{1}, m_{2}, 1+m_{3}\right)^{T}$, where $\Omega$ is the nominal mean angular velocity of the Earth and $\left(m_{1}, m_{2}, m_{3}\right)$ are small variations with respect to constant rotation, the changes $\triangle L O D$ in the length-of-day with respect to the mean length-of-day $L O D_{\text {mean }}$ can be written (Lambeck 1988):

$-\frac{\Delta L O D(t)}{L O D_{\text {mean }}}=m_{3}(t)$

where $L O D_{\text {mean }}=86400$ seconds.

The expression for $m_{3}$ may then be obtained from the Liouville equations, which characterize the rotation of a non rigid Earth, based on the angular momentum conservation (Munk and McDonald 1960):

$m_{3}(t)=-\frac{1}{C_{m} \Omega}\left[h_{3}(t)+\left(1+k_{2}^{\prime}\right) \Omega c_{33}(t)\right]$

where $C_{m}$ is the third principal moment of inertia of the Earth's mantle, $h_{3}$ is the axial relative angular momentum of the Earth (corresponding to the motion term) and $k_{2}^{\prime} c_{33}$ accounts for loading effects in the inertial part of $m_{3}$ (i.e., in the mass term of $m_{3}$; see Barnes et al. 1983). In Eq. (12), the effects of external bodies (Sun and Moon) are not considered, because nowadays they are modeled very properly (McCarthy and Petit 2004).

Combining Eqs. (11) and (12), we further obtain:

$$
\frac{\Delta L O D(t)}{L O D_{\text {mean }}}=\left(1+k_{2}^{\prime}\right) \frac{c_{33}(t)}{C_{m}}+\frac{h_{3}(t)}{C_{m} \Omega}
$$

Finally, on the basis of Eqs. (10) and (13), we can link $\triangle L O D$ with the $C_{20}$ Stokes coefficient variations through:

$\frac{\Delta L O D(t)}{L O D_{\text {mean }}}=-\frac{2}{3 C_{m}} M R_{e}^{2} \Delta C_{20}(t)+\frac{h_{3}(t)}{C_{m} \Omega}$

where it is assumed that $\Delta \operatorname{Tr}(I)=0$, i.e., the trace of the inertia tensor is constant with time.

This assumption (i.e., $\Delta \operatorname{Tr}(I)=0$ ) is true in the case of a closed system (i.e., with no mass loss) such that comprising the entire Earth (solid earth + oceans + atmosphere + hydrosphere) (see Rochester and Smylie 1974). This was verified 


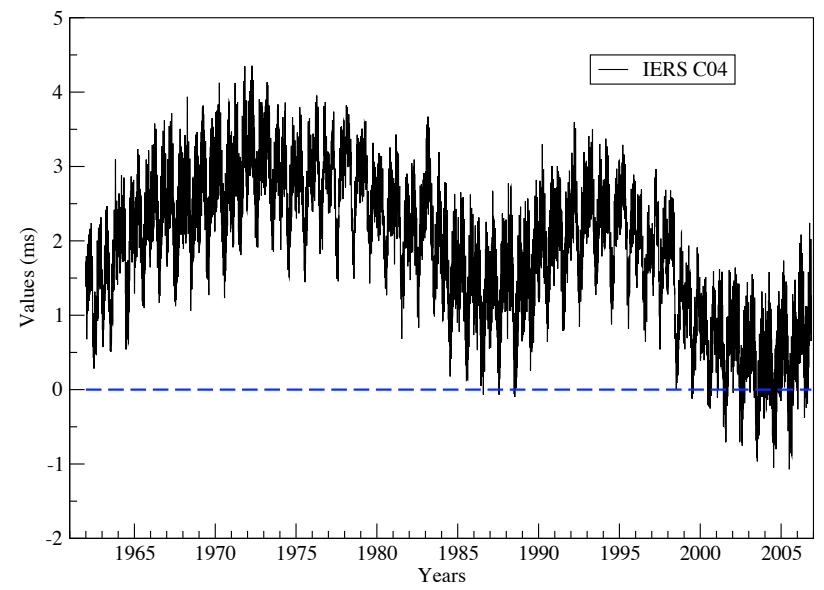

Fig. 1 Observed $\triangle L O D$ data (with respect to $L O D_{\text {mean }}=86400 \mathrm{sec}$ onds) from the IERS-C04 series.

by Chen et al. (2005), who calculated $\Delta \operatorname{Tr}(I)$ from models of atmospheric pressure and terrestrial water storage loads. They conclude that typical annual $\Delta C_{20}$ variability due to $\Delta \operatorname{Tr}(I)$ change is about $10^{-13}$, less than $0.1 \%$ of the variations measured by SLR. Neglecting $\Delta \operatorname{Tr}(I)$ in Eq. (14) is therefore a reasonable assumption.

\section{Data and Processing}

\subsection{Length-of-day astrometric data}

The LOD series used in this study as the basis for the observed $\triangle L O D$ is the IERS-C04 series (Gambis 2004), which covers the period 1962-2006 (see http://hpiers.obspm.fr/eoppc, Fig. 1). As noted above, these measurements refer not only to mass gravitational effects but also to motions into the Earth system.

In order to compare these astrometric data with those obtained from gravity field variations, it is therefore necessary to remove the following contributions from the data: (i) zonal tides, (ii) atmospheric winds, and (iii) oceanic currents. Figure 2 summarizes the successive steps to extract the mass term $\triangle L O D_{\text {astro }}$ from the original IERS-C04 series. The models removed are listed in Table 1 and described in further detail below.

\subsubsection{Zonal tide variations}

The zonal tidal model removed from the IERS-C04 $\triangle L O D$ series is the IERS Conventions 2003 model (Defraigne and Smith 1999). This model covers the period 1962-2006 and the corresponding LOD variations are plotted in Fig. 3.

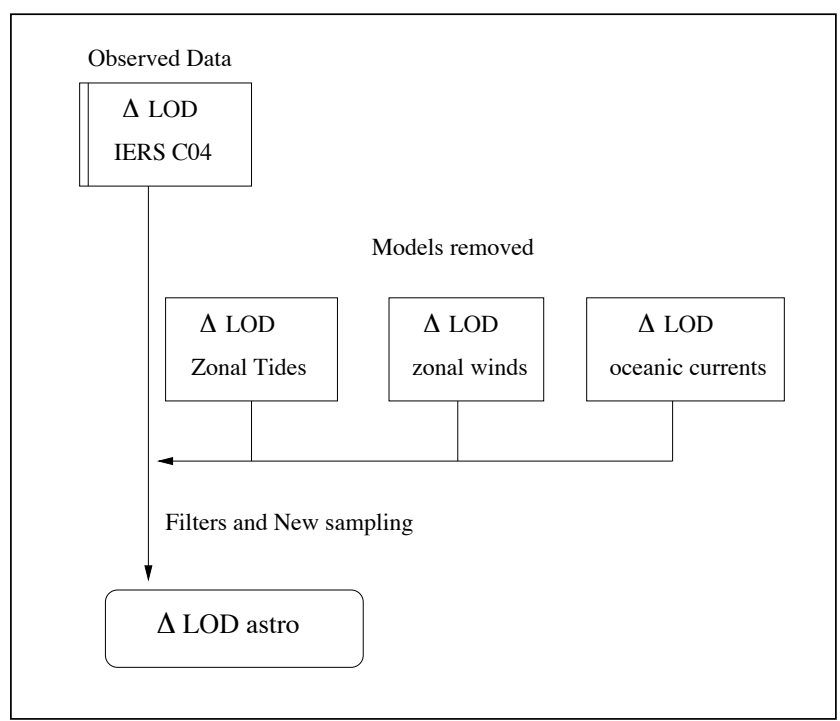

Fig. 2 Diagram explaining the derivation of the astrometric $\triangle L O D$ mass term-series (i.e., $\triangle L O D_{\text {astro }}$ ) from the original $\triangle L O D$ IERS-C04 data.

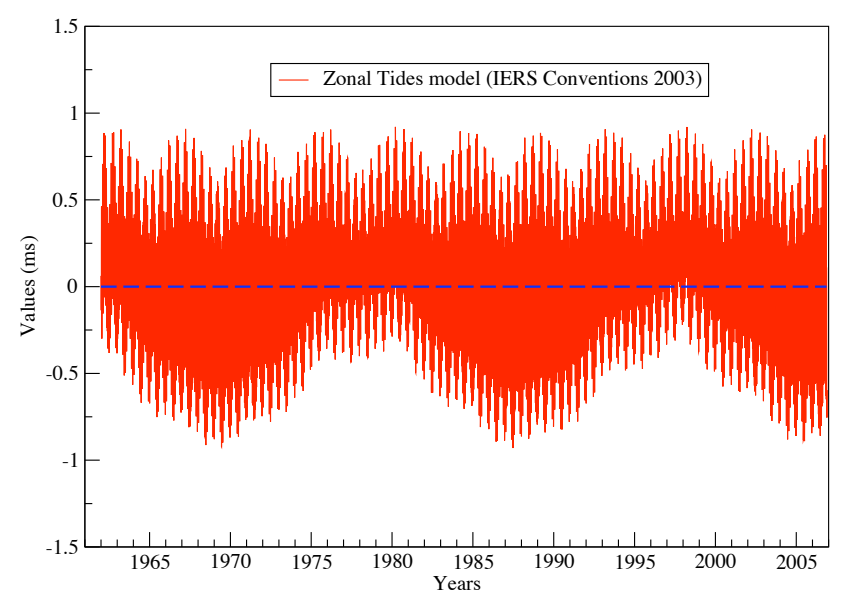

Fig. 3 Zonal tides contribution to $\triangle L O D$ (with respect to $L O D_{\text {mean }}=$ 86400 seconds) as published in the IERS Conventions 2003 model (McCarthy and Petit 2004; Defraigne and Smith 1999).

\subsubsection{Atmospheric Angular Momentum (AAM)}

The motion part of the atmospheric $\triangle L O D$ contribution (zonal winds) is defined by:

$$
\frac{\Delta L O D_{\text {winds }}(t)}{L O D_{\text {mean }}}=\frac{h_{3 \text { winds }}(t)}{C_{m} \Omega}
$$

For our study, it has been calculated from the NCEP (National Centers for Environmental Prediction) reanalysis AAM products for the period 1962-2006 (Fig. 4). These data, in their original form (i.e., as published by the SBA), have a six-hour sampling, but for our analysis we used the series made available by the IERS, which has a 24-hour sampling. 
Table 1 Temporal series used in this study for: (1) the astrometric $\triangle L O D$ calculation, and (2) the gravity field $C_{20}$ derived geodetic $\triangle L O D$ (AAM means Atmospheric Angular Momentum; OAM means Oceanic Angular Momentum).

\begin{tabular}{|c|c|c|c|}
\hline Data & References & Data time span (years) & Time spacing \\
\hline \multicolumn{4}{|c|}{ Astrometric $\triangle L O D$ calculation } \\
\hline Observed $\triangle L O D$ & IERS-C04 (Gambis 2004) & January 1962 - November 2006 & 1 day \\
\hline Zonal Tides model & $\begin{array}{l}\text { IERS Conventions } 2003 \\
\text { (McCarthy and Petit 2004) }\end{array}$ & January 1962 - November 2006 & 1 day \\
\hline AAM: Zonal winds & $\left\{\begin{array}{l}\text { Salstein et al. (1993) } \\
\text { Salstein and Rosen (1997) } \\
\text { Salstein et al. (2005) } \\
\text { Zhou et al. (2006) } \\
\text { Kalnay (1996) }\end{array}\right.$ & January 1962 - November 2006 & 1 day \\
\hline OAM: Zonal currents & $\left\{\begin{array}{l}\text { Gross et al. (2003) } \\
\text { Gross et al. (2004) }\end{array}\right.$ & January 1980 - March 2002 & 1 day \\
\hline \multicolumn{4}{|c|}{ Geodetic $\triangle L O D$ calculation } \\
\hline $\begin{array}{l}\Delta \bar{C}_{20} \text { series } \\
\text { from LAGEOS I \& II } \\
\text { orbitography }\end{array}$ & $\begin{array}{l}\text { Biancale and Lemoine (2004) } \\
\text { Bourda and Capitaine (2004) }\end{array}$ & May 1985 - February 2004 & 10 days \\
\hline
\end{tabular}

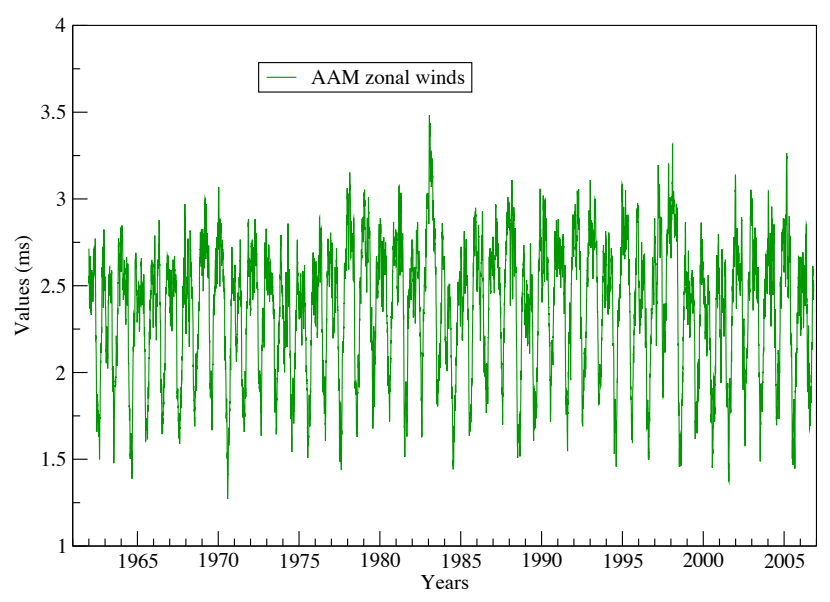

Fig. 4 Atmospheric angular momentum motion contribution (i.e., zonal winds) to $\triangle L O D$ (with respect to $L O D_{\text {mean }}=86400$ seconds).

\subsubsection{Oceanic Angular Momentum (OAM)}

The motion part of the oceanic $\triangle L O D$ contribution (zonal currents) is defined by:

$$
\frac{\Delta L O D_{\text {currents }}(t)}{L O D_{\text {mean }}}=\frac{h_{3 \text { currents }}(t)}{C_{m} \Omega}
$$

This effect has been calculated based on OAM products from the SBO (Gross et al. 2003, 2004) for the period 1980-2002 (http://euler.jpl.nasa.gov/sbo/sbo_data.html, Fig. 5).

\subsubsection{Long-period terms}

After removing the zonal tide, AAM and OAM contributions from the original IERS-C04 $\triangle L O D$ series, long-period

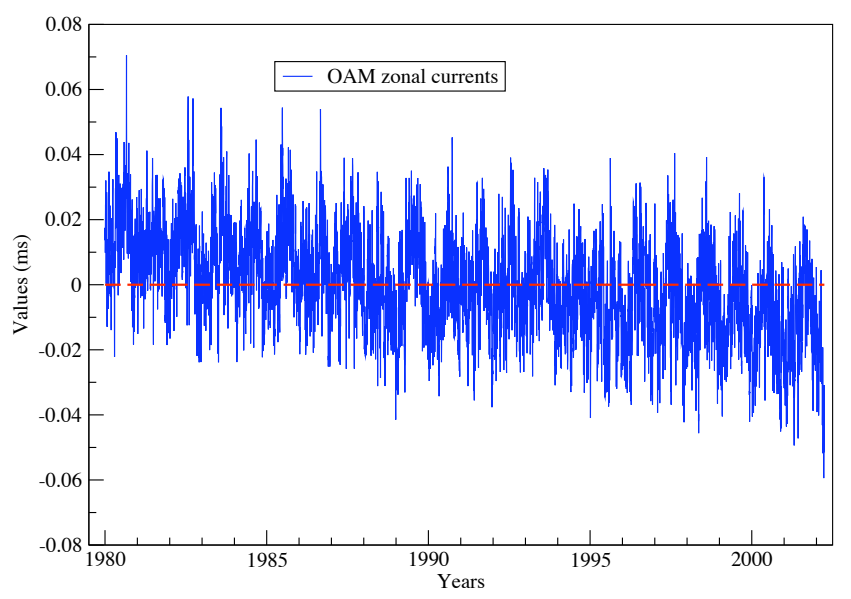

Fig. 5 Oceanic angular momentum motion contribution (i.e., zonal currents) to $\triangle L O D$ (with respect to $L O D_{\text {mean }}=86400$ seconds).

terms (i.e., periods of 10 years or more in Fig. 1) still remain into the resulting series. These are due to coupling between the core and the mantle. As pointed out above, such astrometric $\triangle L O D$ data are referred to the Earth's crust, whereas geodetic $\triangle L O D$ data are referred to the global Earth system. These long-period terms are thus not expected to appear into the gravity-field-derived LOD data. This is the reason why we subtracted these long-period terms from the astrometric $\triangle L O D$ data in an additional processing step. A Vondrak (1977) filter with a half-width period of 1200 days was used for this purpose (this half-width period was aimed at removing the signal with a period longer than 7 years but keeping intact the seasonal signal).

Finally, in order to compare this series with the geodetic $\triangle L O D$ series described in Sect. 3.2 below, we also filtered the high-frequency terms and sampled the data ev- 
ery 10 days. In order to remove all the periodic terms less than 20 days (i.e., corresponding to the Nyquist period for a 10-day sampling), a Vondrak filter was applied with a halfwidth period of 50 days. The astrometric $\triangle L O D$ series thus obtained is denoted as $\triangle L O D_{\text {astro }}$.

\subsection{Gravity field data}

Table 1 provides the characteristics of the gravitational data used to derive the geodetic $\triangle L O D$ mass term on the basis of Eq. (14). These data consist of a series of $\bar{C}_{20}$ fully normalized Stokes coefficient estimates $\left(C_{20}=\sqrt{5} \bar{C}_{20}\right)$ obtained by the GRGS/CNES from fitting the orbits of the LAGEOS I \& II satellites over the period 1985-2004 with the software GINS (Géodésie par Intégrations Numériques Simultanées).

GINS is a multi-technique software, that has been developed for about 30 years by the GRGS/CNES in Toulouse (France), initially for analyzing SLR data, and extended at later stages for analysis of GPS, DORIS, LLR and VLBI data (see for example Coulot et al. 2007). Based on such data, GINS is able to fit the orbit of a satellite around the Earth or another body of the solar system and estimate geophysical parameters (e.g., gravity field coefficients; Biancale et al. 2000; Reigber et al. 2004).

In our case, LAGEOS I and II orbits were derived by fitting the SLR observations with orbital models comprising the equations of motion and surface pressure atmospheric forcing. In this calculation, the fully normalized degree-2 and order- 0 Stokes coefficient $\bar{C}_{20}$ of the gravity field was estimated every 10 days (along with the rest of the degree2 gravity field coefficients), permitting the determination of the total variations $\Delta \bar{C}_{20}$ of this coefficient.

As depicted in Fig. 6, the contributions due to solid Earth tides, atmospheric pressure and oceanic tides were further removed from the $\Delta \bar{C}_{20}$ series (and from the other degree-2 Stokes coefficients) for a more precise gravity field determination by the GRGS. These were calculated based on models for the geopotential from the IERS Conventions 1996 (McCarthy 1996) and using the equations for the $\bar{C}_{20}$ variations given in Bourda and Capitaine (2004).

The $\Delta \bar{C}_{20}$ series delivered by the GRGS/CNES (hereafter referred to as $\bar{C}_{20}$ residual series) is then free from these geophysical effects. Comparing the gravity-field-derived LOD variations with the astrometric $\triangle L O D$ data requires, however, adding back the $\bar{C}_{20}$ variations due to atmospheric pressure (see $\Delta \bar{C}_{20}$ from atmospheric pressure in Fig. 6, removed by the GRGS during the determination of the gravity field; see also Bourda and Capitaine 2004) to this residual series, because atmospheric mass terms are still included into the $\triangle L O D_{\text {astro }}$ data. The resulting series (i.e., that including residual effects and atmospheric pressure variations) is plotted in Fig. 7 along with the original $\Delta \bar{C}_{20}$ total variations (in which the predominant effect comes from the solid Earth tides).

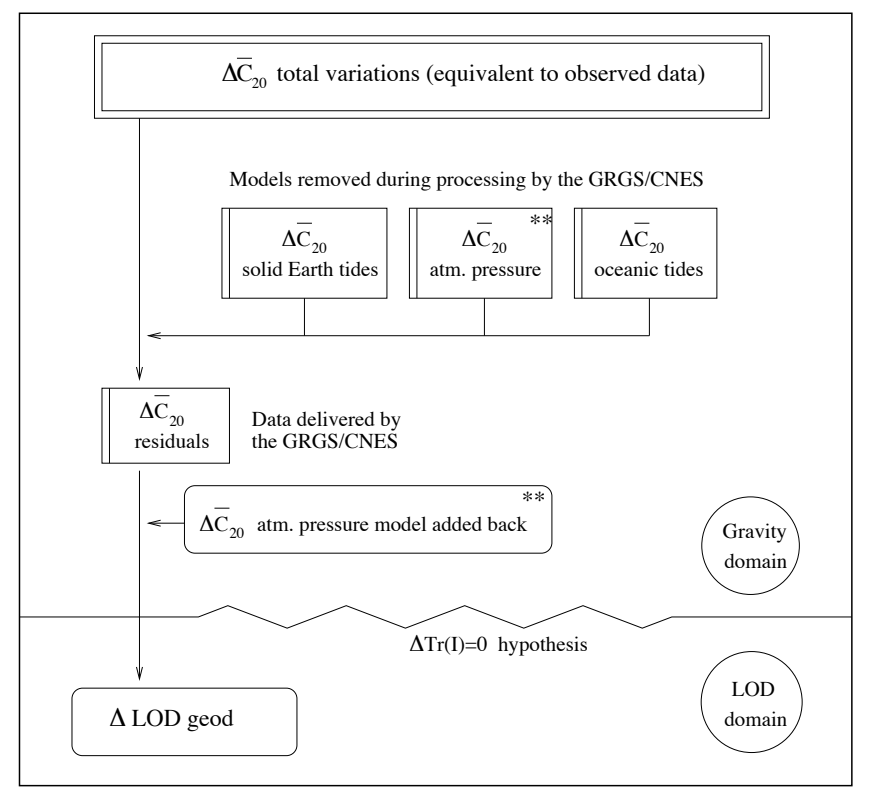

Fig. 6 Diagram explaining the calculation of the geodetic $\triangle L O D$ mass term-series $\left(\triangle L O D_{\text {geod }}\right)$ from the original $\Delta \bar{C}_{20}$ data (** means that the same atmospheric pressure model for $\Delta \bar{C}_{20}$ is used during both steps).

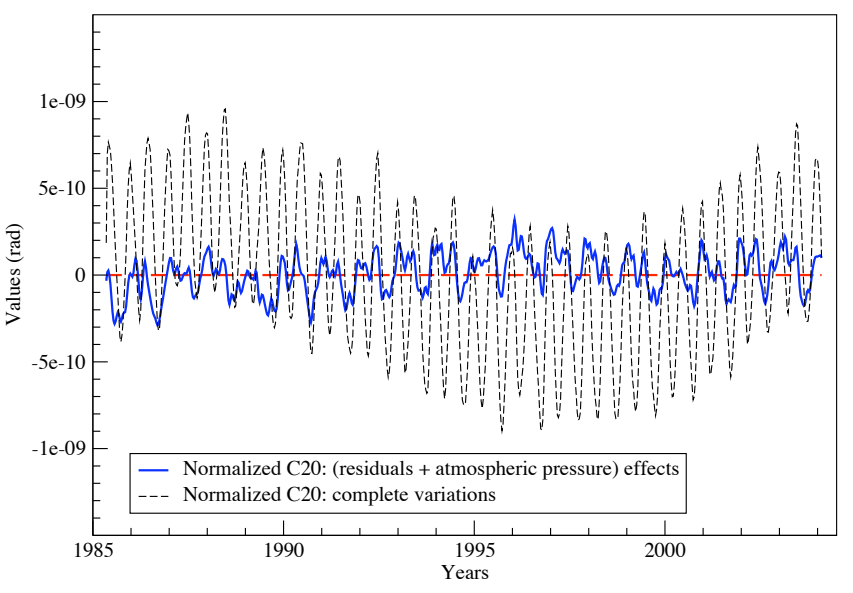

Fig. 7 GRGS series from LAGEOS I and II orbitography for the $\bar{C}_{20}$ variations. The dashed line plots the $\Delta \bar{C}_{20}$ total variations, while the full line plots only the residual effects and atmospheric pressure variations.

From the residual and atmospheric pressure $\Delta \bar{C}_{20}$ data, one can now derive the corresponding LOD variations on the basis of Eq. (14). For this calculation, the fundamental constants listed in Table 2 have been used. In an additional processing step, as already done in the case of the astrometric $\triangle L O D$ mass term-series (to subtract the core-mantle effects), we applied a Vondrak filter with a half-width period of 1200 days. This process was aimed at removing the long-period terms (i.e., longer than 10 years), in order to get homogeneous signal for comparing both $\triangle L O D$ mass termseries. The geodetic $\triangle L O D$ mass term-series obtained at this 
Table 2 Fundamental constants used for the calculation of $\triangle L O D_{\text {geod }}$ (McCarthy and Petit 2004; Barnes et al. 1983).

\begin{tabular}{|c|c|c|}
\hline Parameter & & Value \\
\hline Constant of gravitation & $G$ & $\begin{array}{l}6.673 \times 10^{-11} \\
\mathrm{~m}^{3} \mathrm{~kg}^{-1} \mathrm{~s}^{-1}\end{array}$ \\
\hline $\begin{array}{l}\text { Geocentric gravitational } \\
\text { constant }\end{array}$ & $G M$ & $\begin{array}{l}3.986004418 \times 10^{14} \\
\mathrm{~m}^{3} \mathrm{~s}^{-1}\end{array}$ \\
\hline Mass of the Earth & $M=\frac{G M}{G}$ & $5.9736 \times 10^{24} \mathrm{~kg}$ \\
\hline Equatorial radius of the Earth & $R_{e}$ & $6378136.6 \mathrm{~m}$ \\
\hline $\begin{array}{l}\text { Nominal mean angular } \\
\text { velocity of the Earth }\end{array}$ & $\Omega$ & $\begin{array}{l}7.292115 \times 10^{-5} \\
\operatorname{rad~s}^{-1}\end{array}$ \\
\hline Mean length-of-day & $L O D_{\text {mean }}$ & $86400 \mathrm{~s}$ \\
\hline $\begin{array}{l}\text { Principal moment of inertia } \\
\text { of the Earth's mantle }\end{array}$ & $C_{m}$ & $\begin{array}{l}7.0400 \times 10^{37} \\
\mathrm{~kg} \mathrm{~m}^{2}\end{array}$ \\
\hline Degree-2 loading Love number & $k_{2}^{\prime}$ & -0.30 \\
\hline
\end{tabular}

final stage (denoted as $\triangle L O D_{\text {geod }}$ ) will be the basis for comparing with the astrometric $\triangle L O D$ mass term-series in the next section.

\subsection{Comparisons between $\triangle L O D_{\text {astro }}$ and $\triangle L O D_{\text {geod }}$}

Figure 8 shows the comparison between the astrometric and geodetic $\triangle L O D$ mass term-series, $\triangle L O D_{\text {astro }}$ and $\triangle L O D_{\text {geod }}$ calculated in Sections 3.1 and 3.2, respectively. The atmospheric, oceanic and hydrological mass terms for the LOD variations are still included in these series. The standard deviation of the data (60 $\mu \mathrm{s}$ for $\triangle L O D_{\text {astro }}$ and $44 \mu \mathrm{s}$ for $\left.\triangle L O D_{\text {geod }}\right)$ indicates the magnitude of the corresponding LOD variations. The correlation coefficient between the two series is 0.62 .

Because of the filtering applied during the data processing, the periodic signals that are still present in these series are between 115 and 480 days. In order to extract the annual and semi-annual signals, a Fourier analysis was conducted on both series, the results of which are shown in Fig. 9. After this analysis, the annual and semi-annual signals were further fitted using:

$$
f(t)=A \cos (\omega t+\phi)
$$

where $A$ is the amplitude of the periodic signal, $\omega=2 \pi / T$ is the frequency of the signal ( $T$ being the period) and $\phi$ is the phase. Table 3 and Figure 10 summarize the results of these adjustments for $\triangle L O D_{\text {astro }}$ and $\triangle L O D_{\text {geod }}$.

Finally, these estimated annual and semi-annual signals were removed from the corresponding $\triangle L O D$ series and the Fourier spectra for the residual series were determined again (see Fig. 11). After this operation, the standard deviation of the residuals is $42 \mu \mathrm{s}$ for $\triangle L O D_{\text {astro }}$ and $24 \mu \mathrm{s}$ for $\Delta L O D_{\text {geod }}$, and the correlation between the two series is 0.64 .

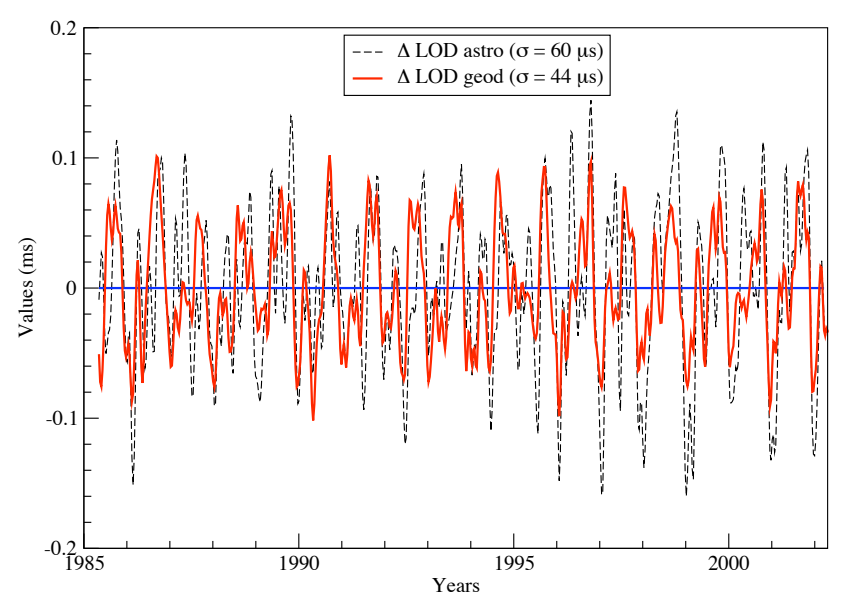

Fig. 8 Astrometric and geodetic $\triangle L O D$ mass term-series with indication of their standard deviation $\sigma$ in $\mu$ s. The correlation between the two series is 0.62 .

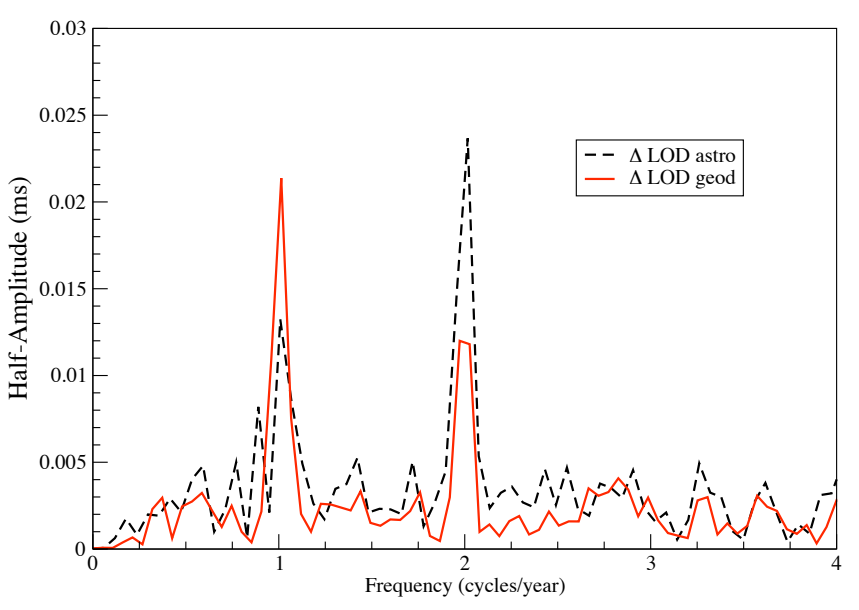

Fig. 9 Fourier spectra of the astrometric and geodetic $\triangle L O D$ mass term-series.

Table 3 Seasonal terms estimated from the astrometric and geodetic $\triangle L O D$ mass term-series.

\begin{tabular}{lcccc}
\hline & \multicolumn{2}{c}{$\Delta L O D_{\text {astro }}$} & \multicolumn{2}{c}{$\Delta L O D_{\text {geod }}$} \\
\hline Period & $\begin{array}{c}\text { Amplitude } \\
\mathrm{ms}\end{array}$ & Phase & $\begin{array}{c}\text { Amplitude } \\
\mathrm{ms}\end{array}$ & Phase \\
\hline Annual & 0.031 & $124^{\circ}$ & 0.044 & $123^{\circ}$ \\
Semi-annual & 0.051 & $146^{\circ}$ & 0.029 & $209^{\circ}$ \\
\hline
\end{tabular}

\section{Discussion}

As noted above, the goal of our study was to compare the LOD variations determined from standard astrometric measurements (as VLBI, GPS, SLR) with those derived from the gravity field variations (see also Yan et al. 2006). To this 

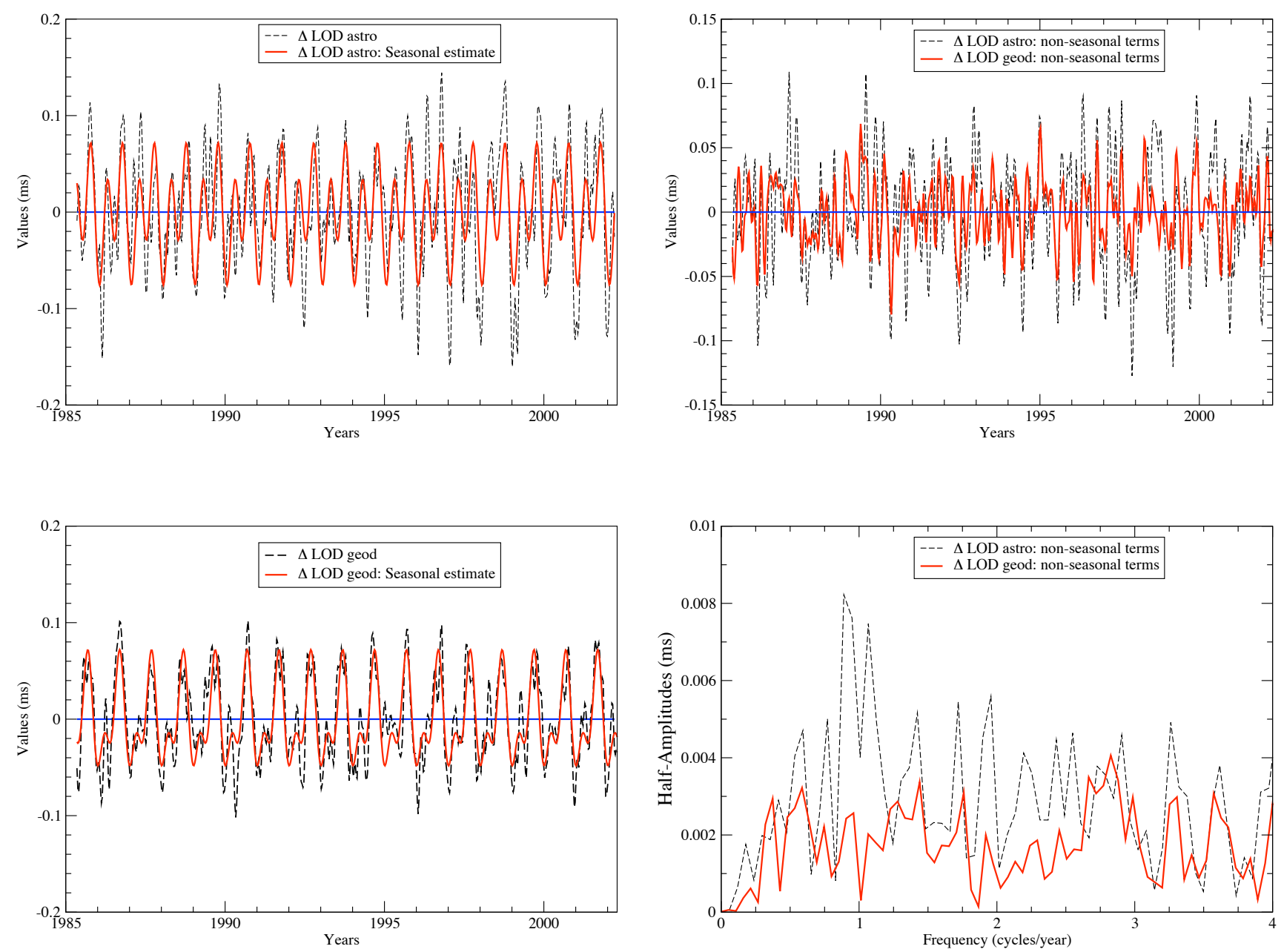

Fig. 10 The $\triangle L O D_{\text {astro }}$ series (upper panel) and the $\triangle L O D_{\text {geod }}$ series (lower panel) with the estimated annual and semi-annual seasonal terms superimposed.

aim, we used LAGEOS I and II SLR gravity field data. Conversely, EOP data have already been used to obtain temporal series of the $C_{20}$ Stokes coefficient, in particular to study long-wavelength gravitational variations independently of SLR measurements or geophysical modeling (Chen et al. 2000; Chen and Wilson 2003; Chen et al. 2005).

Our analysis in Fig. 8 shows a significant correlation (0.62) between the derived astrometric and geodetic $\triangle L O D$ mass term-series, therefore demonstrating the validity of the gravity-field-derived LOD. This is also confirmed when comparing the power spectra for the two series (Fig. 9) and the estimated seasonal signals (annual and semi-annual periods) in Table 3 and Fig. 10, although these show some differences in amplitude.

On one hand, such differences originate because nonidentical tidal models were used in the calculations of $\triangle L O D_{\text {astro }}$ and $\triangle L O D_{\text {geod }}$ in Sects. 3.1 and 3.2. We verified

Fig. 11 Upper panel: the $\triangle L O D_{\text {astro }}$ and the $\triangle L O D_{\text {geod }}$ series without the seasonal terms (annual and semi-annual periods); Lower panel: the corresponding Fourier spectra.

this assumption by recalculating $\triangle L O D_{\text {geod }}$ from the total variations of $\Delta \bar{C}_{20}$ (see Fig. 6) with the same tidal model as that used for $\triangle L O D_{\text {astro }}$ removed from the original data. This test showed closer agreement on the amplitudes of $\triangle L O D_{\text {astro }}$ and $\triangle L O D_{\text {geod }}$ compared to Table 3.

On the other hand, during the processing of $\triangle L O D_{\text {astro }}$, we removed the atmospheric wind effects from the classical LOD measurements, whereas this is the major contribution to the LOD variations (i.e., about $90 \%$ of $\triangle L O D$ ). This involves that small errors in removing the wind contribution can produce large errors in comparing $\triangle L O D_{\text {astro }}$ with $\triangle L O D_{\text {geod }}$. Furthermore, the wind atmospheric angular momentum data used during the calculations are based on models with unknown error bars. These might be constrained using our comparison between $\triangle L O D_{\text {astro }}$ and $\triangle L O D_{\text {geod }}$.

After removing the seasonal terms on the basis of the model from Eq. (17) and Table 3 (see Fig. 11), the correlation between the two series is still similar (0.64 instead of 
0.62). This indicates that there is additional signal common to $\triangle L O D_{\text {astro }}$ and $\triangle L O D_{\text {geod }}$ besides that contained in the seasonal terms. This is confirmed when comparing the two spectra (Fig. 11), which show similar behaviour at several periods, although the signal is roughly at the precision level of the LOD data (i.e., 5-10 $\mu$ s). The most important correlation is found near the period of 120 days (i.e., $\simeq 3$ cycles per year) and the corresponding signal has an amplitude of 8-10 $\mu$ s (see Fig. 11).

To further investigate this four-month signal, it would be interesting to do a comparison with an hydrology-derived LOD mass term-series, like the LaD (Land Dynamics model) hydrological model (Milly and Shmakin 2002). Chen and Wilson (2003) already initiated such a study, by comparing the $\Delta C_{20}$ series derived from LDAS (Land Data Assimilating System; Fan et al. 2003) hydrological model (from the NCEP Climate Prediction Center) and from SLR data. They revealed interesting correlations at interannual and intraseasonal time-scales, along with Bourda (2004) including one signal near the period 120 days similar to that found in our analysis.

\section{Conclusion}

The work presented here was aimed at underlying the possibility of using gravity field data to determine LOD variations. This was envisioned because of the relationship existing between the LOD and the gravity field (through the inertia tensor). As a result, gravity field measurements could become a new source of data for determining the EOP, independent of the current space-geodetic data.

In order to investigate this relationship, we compared two types of data: (i) the standard LOD series derived by the IERS from a combination of space-geodetic techniques results (primarily VLBI, GPS and SLR), and (ii) the gravity field variations obtained by the GRGS/CNES from the orbitography of the LAGEOS I and II satellites and represented by a series of the degree- 2 and order- 0 Stokes coefficient $C_{20}$.

From this study, it is found that the geodetic LOD mass term variations derived from $\Delta C_{20}$ show a good correlation with those observed in the standard astrometric LOD data. The seasonal terms (annual and semi-annual periods) are similar and there is also additional signal (intraseasonal signal) at a level $<10 \mu$ s common to the spectra of the two series. This demonstrates that the gravity-field-derived LOD is very valuable and could be a useful supplement to current LOD determinations.

The remaining differences between the LOD mass term variations from classical measurements and gravity field data might be also a good way to quantify the errors nowadays remaining unknown in the atmospheric wind angular momentum data.

An interesting specific signal is found in both $\triangle L O D$ mass term-series at a period of about 120 days. This signal is suspected to be caused by hydrological effects and we plan to investigate it further by using recent geophysical models. Comparing the polar motion coordinates with the $C_{21}$ and $S_{21}$ gravity field Stokes coefficients variations on the basis of SLR and GRACE measurements (Lemoine et al. 2007) would also be worthwhile to further constrain polar motion estimates (Bourda 2005; Chen and Wilson 2005).

Ultimately, the goal of all such studies is a better understanding of the Earth's global dynamics, including couplings into the Earth system, e.g. between hydrological effects and Earth rotation parameters, or core-mantle couplings. As noted previously, this work is also important in the framework of the GGOS project of the IAG to unify the Earth's geometry, gravity field and dynamics.

Acknowledgements The author thanks Nicole Capitaine for proposing this work on the relationships between EOP and gravity field variations, and the GRGS/CNES team for providing the LAGEOS gravity field data used in this study. The author is grateful to the CNES (Centre National d'Etudes Spatiales, France) for the post-doctoral position granted at Bordeaux Observatory. The author acknowledges also the Advisory Board of the Descartes-Nutations prize for the six-month fellowship at the Institute of Geodesy and Geophysics (Technical University of Vienna) in 2005 to pursue this study. Finally, the author is grateful to Patrick Charlot for critically reading an earlier version of this manuscript.

\section{References}

Barnes R, Hide R, White A, Wilson C (1983) Atmospheric angular momentum fluctuations, length-of-day changes and polar motion. Proc R Soc Lond A 387(1792): 31-73

Biancale R, Balmino G, Lemoine J-M, Marty J-C, Moynot B, Barlier F, Exertier P, Laurain O, Gegout P, Schwintzer P, Reigber Ch, Bode A, Konig R, Massmann F-H, Raimondo J-C, Schmidt R, Zhu SY (2000) A New Global Earth's Gravity Field Model from Satellite Orbit Perturbations: GRIM5-S1. Geophys Res Lett 27(22): 36113614 DOI: $10.1029 / 2000$ GL011721

Biancale R, Lemoine J-M (2004) Private communication about the $C_{20}$ data from LAGEOS I and II orbitography

Bourda G, Capitaine N (2004) Precession, Nutation, and space geodetic determination of the Earth's variable gravity field. A\&A 428: 691-702 DOI: 10.1051/0004-6361:20041533

Bourda G (2004) Earth rotation and gravity field variations: Study and contribution of the missions CHAMP and GRACE. $\mathrm{PhD}$ Thesis, Paris Observatory, France - http://tel.archivesouvertes.fr/documents/archives0/00/00/82/86/index_fr.html

Bourda G (2005) Length of day and polar motion, with respect to temporal variations of the Earth gravity field. In: Casoli F, Contini T, Hameury J and Pagani L (eds) EdP-Sciences, Conference Series, pp 115-116

Chao B, Gross R (1987) Changes in the Earth's rotation and low-degree gravitational field induced by earthquakes. Geophys J Roy Astron Soc 91: 569-596

Chao B, Au A (1991) Temporal variation of the Earth's lowdegree zonal gravitational field caused by atmospheric mass redistribution - 1980-1988. J Geophys Res 96(B4): 6577-6582 DOI: $10.1029 / 91 \mathrm{JB} 00041$

Chao B (1994) The Geoid and Earth Rotation. In: Vanicek P, Christou N (eds) The Geoid and its Geophysical Interpretation. CRC Press Boca Rathon, pp 285-298

Chao B, Eanes R (1995) Global gravitational changes due to atmospheric mass redistribution as observed by LAGEOS nodal residual. Geophys J Int 122(3): 755-764 DOI: 10.1111/j.1365246X.1995.tb06834.x 
Chao B (2005) On inversion for mass distribution from global timevariable gravity field. Journal of Geodynamics 39(3): 223-230 DOI: $10.1016 /$ j.jog.2004.11.001

Chen J, Wilson C, Eanes R, Tapley B (2000) A new assessment of long-wavelength gravitational variations. J Geophys Res 105(B7): 16271-16278 DOI: 10.1029/2000JB900115

Chen J, Wilson C (2003) Low degree gravitational changes from Earth rotation and geophysical models. Geophys Res Lett 30(24): 22572260, DOI 10.1029/2003GL018688

Chen J, Wilson C, Tapley B (2005) Interannual variability of lowdegree gravitational change, 1980-2002. Journal of Geodesy 78(9): 535-543 DOI: 10.1007/s00190-004-0417-y

Chen J, Wilson C (2005) Hydrological excitations of polar motion, 1993-2002. Geophys J Int 160(3): 833-839 DOI: 10.1111/j.1365246X.2005.02522.X

Cheng M, Shum C, Tapley B (1997) Determination of longterm changes in the Earth's gravity field from satellite laser ranging observations. J Geophys Res 102(B10): 22377-22390 DOI: $10.1029 / 97 J B 01740$

Cheng M, Tapley B (1999) Seasonal Variations in low-degree zonal harmonics of the Earth's gravity field from satellite laser ranging observations. J Geophys Res 104(B2): 2667-2682 DOI: $10.1029 / 1998 J B 900036$

Coulot D, Berio P, Biancale R, Loyer S, Soudarin L, Gontier A-M (2007) Toward a direct combination of space-geodetic techniques at the measurement level: Methodology and main issues. J Geophys Res 112: B05410 DOI 10.1029/2006JB004336

Cox C, Chao B (2002) Detection of a Large-Scale Mass Redistribution in the Terrestrial System Since 1998. Science 297(5582): 831-833 DOI: $10.1126 /$ science. 1072188

Defraigne P, Smits I (1999) Length of day variations due to zonal tides for an elastic Earth in non-hydrostatic equilibrium. Geophys J Int 139(2): 563-572 DOI: 10.1046/j.1365-246x.1999.00966.x

Dickey J, Williams J (1983) Earth Rotation from lunar laser ranging. A\&A Supp Ser 54: 519-540

Dickey J, Marcus S, De Viron O, Fukumori I (2002) Recent Earth Oblateness Variations: Unraveling Climate and Postglacial Rebound Effetcs. Science 298(5600): 1975-1977 DOI: 10.1126/science. 1077777

Eubanks TM (1993) Variations in the orientation of the Earth. In: Smith D, Turcotte D (eds) Contributions of space geodesy to geodynamics: Earth dynamics. Geodyn Ser 24, American Geophysical Union, Washington, pp 1-54

Fan Y, Van del Dool H, Mitchell K, Lohmann D (2003) A 51-year reanalysis of the U.S. land-surface hydrology. GEWEX News 13(2): $6-10$

Farrel W (1972) Deformation of the Earth by surface loads. Rev Geophys Space Phys 10: 761-797

Gambis D (2004) Monitoring Earth orientation using space-geodetic techniques: state-of-the-art and prospectives. Journal of Geodesy 78: 295-303 DOI: 10.1007/s00190-004-0394-1

Gambis D (2006) DORIS and the determination of the Earth's polar motion. J Geod 80(8-11): 649-656 DOI: 10.1007/s00190-0060043-y

Gegout P, Cazenave A (1993) Temporal Variations of the Earth Gravity Field for 1985-1989 derived from LAGEOS. Geophys J Int 114(2): 347-359 DOI: 10.1111/j.1365-246X.1993.tb03923.x

Gross R (2001) Gravity, Oceanic Angular Momentum and the Earth's Rotation. In: Gravity, Geoid and Geodynamics 2000. IAG Symposia 123, Sideris, Springer New-York, pp 153-158

Gross R, Fukumori I, Menemenlis D (2003) Atmospheric and Oceanic Excitation of the Earth's Wobbles During 1980-2000. J Geophys Res 108(B8): 2370 DOI: 10.1029/2002JB002143

Gross R, Fukumori I, Menemenlis D, Gegout P (2004) Atmospheric and Oceanic Excitation of Length-of-Day Variations During 1980-2000. J Geophys Res 109(B1): B01406 DOI: $10.1029 / 2003 J B 002432$

Kalnay E (1996) The NCEP/NCAR 40-year reanalysis project. Bull Amer Meteor Soc 77: 437-471

Kaula W (1966) Theory of Satellite Geodesy. Blaisdell, Waltham
Lambeck K (1988) Geophysical Geodesy: The Slow Deformations of the Earth. Oxford University Press, Oxford

Lemoine J-M (2004) Private communication on the comparison between SLR and GRACE gravity field variation determination

Lemoine J-M, Bruinsma S, Loyer S, Biancale R, Marty J-C, Perosanz F, Balmino G (2007) Temporal gravity field models inferred from GRACE data. Advances in Space Research DOI: $10.1016 /$ j.asr.2007.03.062

Lichten S, Marcus S, Dickey J (1992) Sub-daily resolution of Earth rotation variations with Global Positionning System measurements. Geophys Res Lett 19: 537-540 DOI: 10.1029/92GL00563

McCarthy D (1996) IERS Conventions 1996. IERS Technical Note 21, Observatoire de Paris, Paris

McCarthy D, Petit G (2004) IERS Conventions 2003. IERS Technical Note 32, Frankfurt am Main: Verlag des Bundesamts fr Kartographie und Geodsie, paperback, ISBN 3-89888-884-3 (print version)

Milly P, Shmakin A (2002) Global Modeling of Land Water and Energy Balances-Part I: The Land Dynamics (LaD) Model. Journal of Hydrometeorology 3(3): 283-299 DOI: 10.1175/1525-7541

Munk W, McDonald G (1960) The rotation of the Earth. Cambridge University Press, Cambridge

Nerem R, Chao B, Au A, Chan J, Klosko S, Pavlis N, Williamson R (1993) Temporal Variations of the Earth's Gravitational Field from Satellite Laser Ranging to LAGEOS. Geophys Res Let 20(7): 595598 DOI: 10.1029/93GL00169

Reigber C, Balmino G, Schwintzer P, Biancale R, Bode A, Lemoine J-M, Koenig R, Loyer S, Neumayer H, Marty J-C, Barthelmes F, Perosanz F, Zhu S (2002) A high quality global gravity field model from CHAMP GPS tracking data and Accelerometry (EIGEN-1S). Geophys Res Lett 29(14): 1692 DOI: 10.1029/2002GL015064

Reigber C, Jochmann H, Wunsch J, Petrovic S, Schwintzer P, Barthelmes F, Neumayer K-H, Konig R, Forste Ch, Balmino G, Biancale R, Lemoine J-M, Loyer S, Perosanz F (2004) Earth Gravity Field and Seasonal Variability from CHAMP. In: Reigber Ch, Luhr H, Wickert J (eds) Earth Observation with CHAMP Results from Three Years in Orbit. Springer, Berlin, Heidelberg, New York, pp 25-30

Reigber C, Schmidt R, Flechtner F, König R, Meyer U, Neumayer K, Schwintzer P, Zhu S (2005) An Earth gravity field model complete to degree and order 150 from GRACE: EIGEN-GRACE02S. Journal of Geodynamics 39(1): 1-10 DOI: 10.1016/j.jog.2004.07.001

Rochester M, Smylie D (1974) On changes in the trace of the Earth's inertia tensor. J Geophys Res 79(2): 4948-4951

Rubincam D (1984) Postglacial Rebound Observed by LAGEOS and the Effective Viscosity of the Lower Mantle. J Geophys Res 89: 1077-1087

Rummel R, Rothacher M, Beutler G (2005) Integrated Global Geodetic Observing System (IGGOS) - science rationale. Journal of Geodynamics 40(4-5): 357-362 DOI: 10.1016/j.jog.2005.06.003

Salstein D, Kann D, Miller A, Rosen R (1993) The Sub-bureau for Atmospheric Angular Momentum of the International Earth Rotation Service: A Meteorological Data Center with Geodetic Applications. Bull Amer Meteor Soc 74: 67-80

Salstein D, Rosen R (1997) Global momentum and energy signals from reanalysis systems. Preprints - 7th Conf on Climate Variations. American Meteorological Society, Boston, pp 344-348

Salstein D, Zhou Y, Chen J (2005) Revised angular momentum datasets for atmospheric angular momentum studies. European Geophysical Union (EGU) Spring Meeting, Vienna

Schlüter W, Behrend D (2007) The International VLBI Service for Geodesy and Astrometry (IVS): current capabilities and future prospects. Journal of Geodesy 81(4-5): 379-387 DOI: $10.1007 / \mathrm{s} 00190-006-0131-\mathrm{z}$

Schuh H, Schmitz-Hübsch H (2000) Short period Variations in Earth rotation as seen by VLBI. Surveys in Geophysics 21(5): 499-520 DOI: $10.1023 / \mathrm{A}: 1006769727728$

Tapley B, Schultz B, Eanes R (1985) Station coordinates, baselines, and Earth rotation from LAGEOS laser ranging - 1976-1984. J Geophys Res 90: 9235-9248 
Tapley B, Schutz B, Eanes R, Ries J, Watkins M. (1993) LAGEOS Laser Ranging Contributions to Geodynamics, Geodesy, and Orbital Dynamics. In: Smith D, Turcotte D (eds) Contributions of space geodesy to geodynamics: Earth dynamics. Geodyn Ser 24, AGU, Washington, pp 147-173

Vondrak J (1977) Problem of smoothing observational data II. Bull Astron Inst Czech 28: 84-89

Yan H, Zhong M, Zhu Y, Liu L, Cao X (2006) Nontidal oceanic contribution to length-of-day changes estimated from two ocean models during 1992-2001. J Geophys Res 111(B2): B02410 DOI: $10.1029 / 2004 J B 003538$

Yoder C, Williams J, Dickey J, Shutz B, Eanes R, Tapley B (1983) Secular variation of Earth's gravitational harmonic J2 coefficient from LAGEOS and nontidal acceleration of earth rotation. Nature 303: 757-762

Zhou Y, Salstein D, Chen J (2006) Revised atmospheric excitation function series related to Earth variable rotation under consideration of surface topography. J Geophys Res 111(D12): D12108 DOI: $10.1029 / 2005 J D 006608$ 